\title{
Conventional and dual competitive binding analyses of thyroxine using the Thyopac-4 $\mathrm{kit}^{1}$
}

\author{
SATOSHI HAMADA, KANJI TORIZUKA, AND TETSUO UETE \\ From the Radioisotope Research Centre, Kyoto University, the Department of Radiology, Kyoto University \\ School of Medicine, Kyoto, and the Division of Clinical Biochemistry, Kitano Hospital, Osaka, Japan
}

SYNOPSIS A simple method is described for the simultaneous determinations of thyroxine and the effective thyroxine ratio (ETR) using a single kit of Thyopac-4. Thyopac ETR values obtained were $1.00 \pm 0.03$ for normal subjects; $1.22 \pm 0.11$ for hyperthyroid; $0.87 \pm 0.04$ for hypothyroid; and $1.02 \pm 0.05$ for pregnant women. Cases with TBG deficiency and the nephrotic syndrome indicated normal values. The value $(x)$ was correlated significantly $(\gamma=+0.961)$ with the free Thyopac index $(y)$, representing a regression equation of $y=71 \cdot 7 x^{2}-88 \cdot 4 x+24 \cdot 2$. Thyopac ETR was shown to be useful in differentiating normal thyroid states from abnormal, irrespective of changes in $\mathrm{T}_{4}$-binding globulin (TBG). Further, the $T_{4}$ value obtained simultaneously made it possible to detect changes in the TBG level by noting an inconsistent value for the effective thyroxine ratio.

It is known that free thyroxine $\left(\mathrm{T}_{4}\right)$ in serum enters peripheral cells directly related to hormonal action, and therefore that its concentration is the best indicator of thyroid status (Robbins and Rall, 1960). However, equilibrium dialysis or ultrafiltration to measure free $T_{4}$ is so laborious that various kinds of free $T_{4}$ indices were devised to be calculated from the $T_{4}$ value and triiodothyronine $\left(\mathrm{T}_{3}\right)$ resin uptake (Clark and Horn, 1965; Goolden, Gartside, and Sanderson, 1967; Hamada, Nakagawa, Mori, and Torizuka, 1970). Further, dual competitive binding analyses such as the effective thyroxine ratio (ETR) (Mincey, Thorson, Brown, Morrison, and McIntosh, 1971) and the normalized serum thyroxine $\left(\mathrm{T}_{4} \mathrm{~N}\right)$ (Ashkar and Bezjian, 1972) have recently been introduced as other indicators of free $\mathrm{T}_{4}$ level.

The present paper describes a simple method for simultaneous determinations of serum $\mathrm{T}_{4}$ and Thyopac ETR ${ }^{2}$ by a single kit of Thyopac-4. Laboratory tests of thyroid status have provided corroboration for the validity of the present method.

\footnotetext{
${ }^{1}$ This paper was presented in part at the annual meeting of the Japan Endocrinological Society, April 9-11, 1973.

'Res-O-Mat effective thyroxine ratio is a trademark of Mallinckrodt Chem. Works. The dual competitive binding analysis using a Thyopac-4 kit was called tentatively Thyopac ETR.
}

Received for publication 3 January 1974.

\section{Materials and Methods}

Sera were tested from 86 patients in the Central Radioisotope Division of Kyoto University Hospital and the Division of Clinical Biochemistry and Obstetric Clinic of Kitano Hospital. Forty were euthyroid subjects, 18 were patients with hyperthyroidism, 14 were patients with primary hypothyroidism, 12 were pregnant women in the second and third trimesters, one was a patient with congenital TBG deficiency, and one with the nephrotic syndrome.

Thyopac-3 and Thyopac- 4 kits were available from the Radiochemical Centre, Amersham, England.

Thyopac-3 values were determined according to the instructions. The free Thyopac index was calculated by the following formula using Thyopac-3 and Thyopac-4 values: free Thyopac index $=100 \times$ Thyopac- $4 \div$ Thyopac- 3 .

DETERMINATION OF T4 AND THYOPAC ETR BY THYOPAC-4 KIT

1 Add $0.5 \mathrm{ml}$ of unknown serum, standard reference sera, or normal pooled serum to $1.0 \mathrm{ml}$ of ethanol in an extraction tube and stopper. Shake briskly. Standard sera and normal pooled serum should be duplicated.

2 Mix for two min by rotation.

3 Centrifuge for five min at $2000 \mathrm{rpm}$.

4 Accurately pipette $0.5 \mathrm{ml}$ of clear extract 
supernatant liquid into a Thyopac-4 vial, and stopper.

5 Mix the contents of each vial at room temperature for $30 \mathrm{~min}$ by rotation.

6 Allow granules to settle for two minutes.

7 Remove $1.0 \mathrm{ml}$ supernatant liquid from the vial and transfer to a counting tube suitable for ${ }^{125} \mathrm{I}$. Count each sample for not less than 20000 counts.

8 For each sample determine $\frac{10^{7}}{\text { counts }-\mathrm{BG}}=\frac{1}{\mathrm{C}}$.

Calculate the mean value of $\frac{1}{\mathrm{C}}$ for each standard and draw a calibration line.

9 Pipette $5 \mu$ l of each unknown serum or normal pooled serum into corresponding Thyopac-4 vials and stopper.

10 Mix the contents of each vial at room temperature for $\mathbf{3 0}$ minutes.

11 Allow granules to settle for two minutes.

12 Remove $1.0 \mathrm{ml}$ supernatant liquid from the vial and transfer to the same type of counting tube as used in the step 7. Count each sample for not less than 20000 counts.

13 For each sample determine Thyopac ETR as

$$
\text { follows: } \frac{\text { Normal pool counts - BG }}{\text { Patient serum counts - BG }}
$$

Steps 5 to 8 may be omitted to determine Thyopac ETR only.

\section{Results}

A summary of the results obtained is shown in table I.

A scattergram for Thyopac-3 and -4 values is shown in figure 1 . In the majority of pregnant women and in the TBG-deficient subject, the values for Thyopac-3 and -4 differed by more than 2

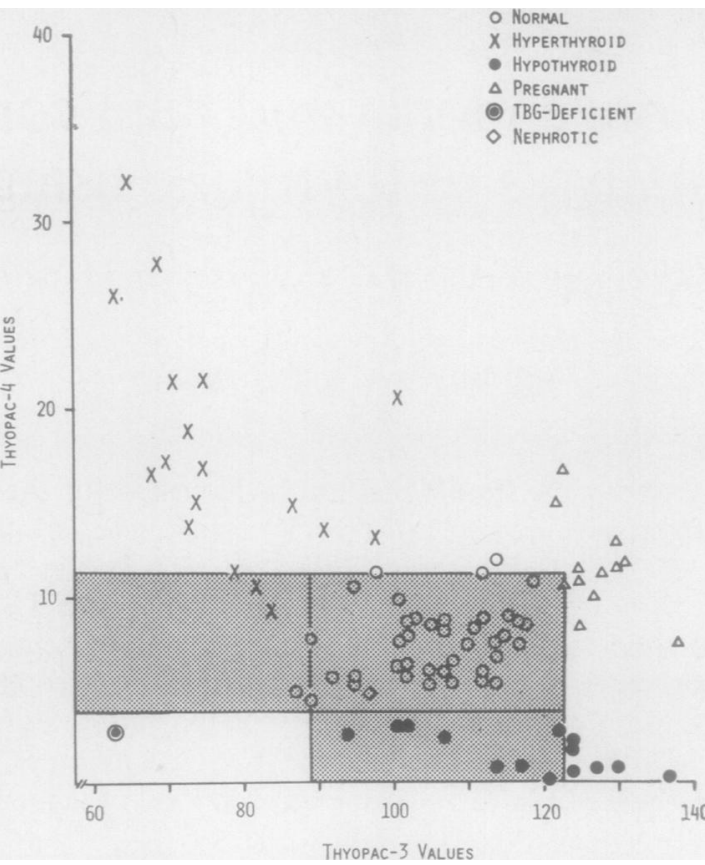

Fig 1 Thyopac-3 and -4 values in various thyroid conditions. The shaded area indicates a range of 2 standard deviations from the mean normal value.

standard deviations from the mean normal value, corroborating previous observations (Clark and Brown, 1970a).

On the other hand, the free Thyopac index for pregnant women and the TBG-deficient subject remained within the normal range as shown in figure 2 . Values for hyper- and hypothyroidism were significantly different $(P=0.005)$ from the normal value. The results obtained were consistent with a previous report (Clark and Brown, 1970b).

A scattergram for Thyopac ETR is shown in

\begin{tabular}{|c|c|c|c|c|c|}
\hline & $\begin{array}{l}\text { No. of } \\
\text { Cases }\end{array}$ & $\begin{array}{l}\text { Thyopac-4 } \\
(\mu \mathrm{g} / 100 \mathrm{ml})\end{array}$ & Thyopac-3 & Free Thyopac Index & Thyopac ETR \\
\hline $\begin{array}{l}\text { Normal } \\
\text { Hyperthyroid }\end{array}$ & $\begin{array}{l}40 \\
18\end{array}$ & $\begin{array}{l}7.6 \pm 1.9^{1} \\
17.9 \pm 6.2 \\
(0.005)^{2}\end{array}$ & $\begin{array}{l}106 \pm 9 \\
78 \pm 11 \\
(0.005)\end{array}$ & $\begin{array}{l}7 \cdot 2 \pm 1 \cdot 8 \\
24.0 \pm 10 \cdot 7 \\
(0.005)\end{array}$ & $\begin{array}{l}1.00 \pm 0.03 \\
1.22 \pm 0.11 \\
(0.005)\end{array}$ \\
\hline Hypothyroid & 14 & $\begin{array}{l}1.6 \pm 1 \cdot 1 \\
(0.005)\end{array}$ & $\begin{array}{l}117 \pm 12 \\
(0.01)\end{array}$ & $\begin{array}{l}1.4 \pm 1 \cdot 1 \\
(0.005)\end{array}$ & $\begin{array}{l}0.87 \pm 0.04 \\
(0.005)\end{array}$ \\
\hline Pregnant & 12 & $\begin{array}{l}11.5 \pm 2.5 \\
(0.005)\end{array}$ & $\begin{array}{l}127 \pm 5 \\
(0.005)\end{array}$ & $\begin{array}{l}9 \cdot 1 \pm 2 \cdot 2 \\
(0 \cdot 025)\end{array}$ & $\begin{array}{l}1.02 \pm 0.05 \\
(\mathrm{NS})^{2}\end{array}$ \\
\hline $\begin{array}{l}\text { TBG deficient } \\
\text { Nephrotic }\end{array}$ & $\begin{array}{l}1 \\
1\end{array}$ & $\begin{array}{l}2.8 \\
4.8\end{array}$ & $\begin{array}{l}63 \\
97\end{array}$ & $\begin{array}{l}4.4 \\
5.0\end{array}$ & $\begin{array}{l}0.96 \\
0.96\end{array}$ \\
\hline
\end{tabular}

Table 1 Summary of the results obtained in various states of thyroid function

${ }^{1}$ Mean \pm SD

${ }^{2}$ Probability that the value in the test group is identical with the corresponding value in the normal group.

NS = not significant $(P<0 \cdot 1)$. 

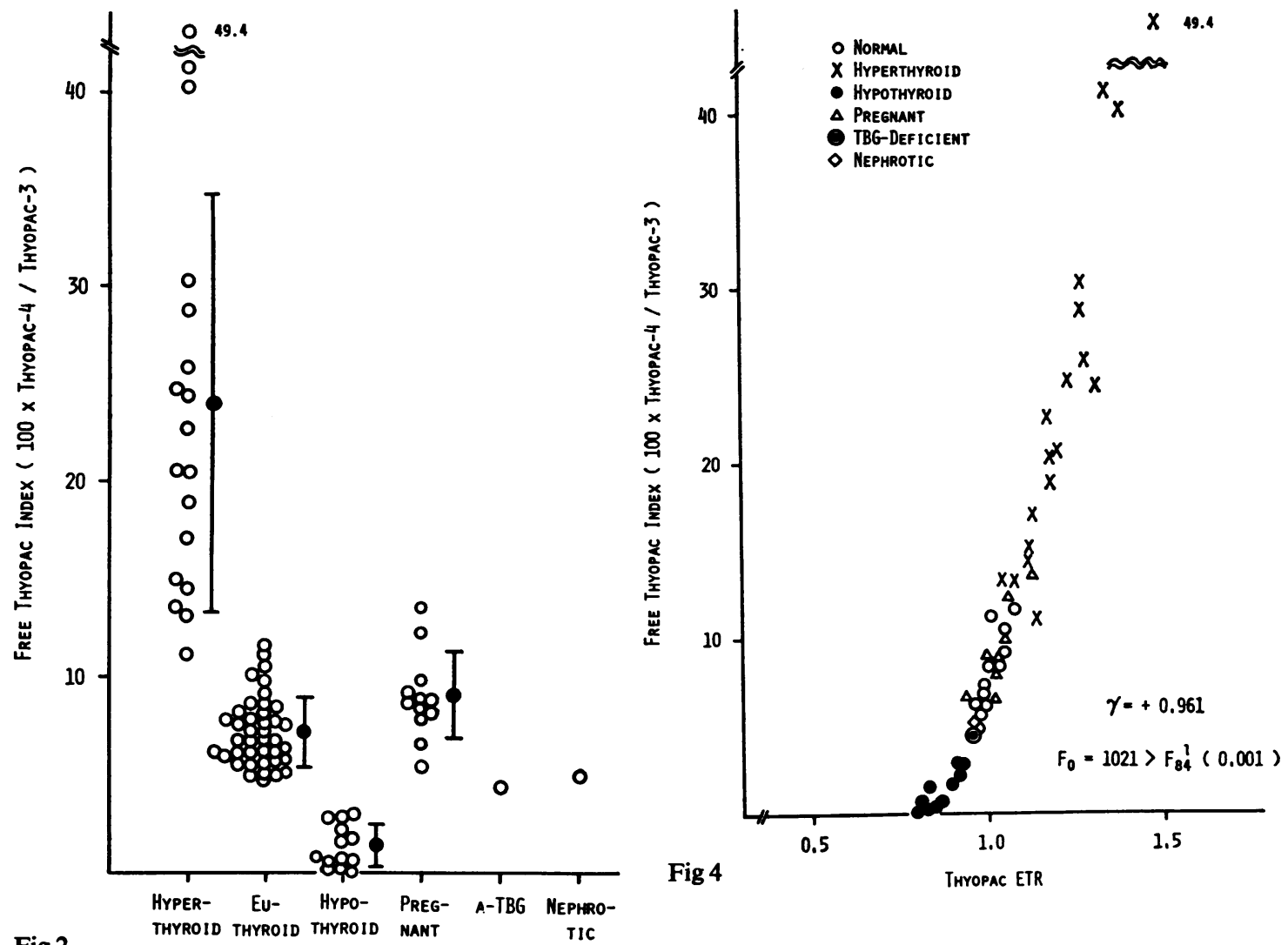

Fig 2

Fig 4

ThYOPAC ETR

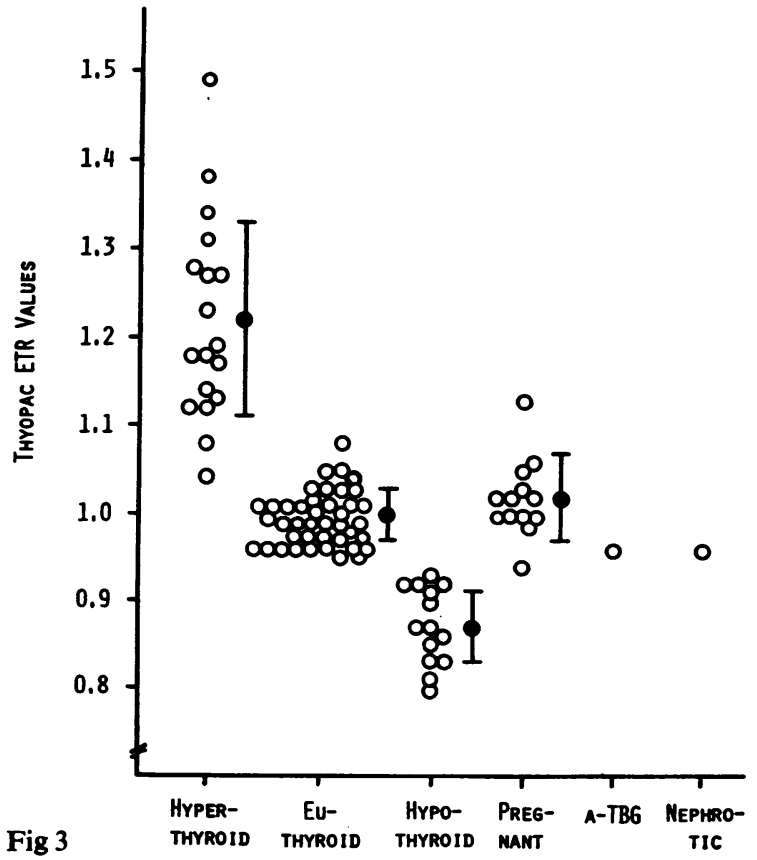

Fig 2 Free Thyopac index in various thyroid conditions. Closed circles indicate mean values, and bars show a range of 1 standard deviation from the mean.

Fig 3 Thyopac ETR values in various thyroid conditions.

Fig 4 Relationship between Thyopac ETR $(x)$ and free Thyopac index (y), expressed by regression equation of $\mathrm{y}=71 \cdot 67 \mathrm{x}^{2}-88 \cdot 40 \mathrm{x}+24 \cdot 18$

Fig 3

THYROID THYROID THYROID MANT 
figure 3. The values for normal subjects ranged from 0.93 to 1.08 , and differed significantly $(P=0.005)$ from those for hyper- and hypothyroidism. In pregnant women and the TBG-deficient subject, the values obtained remained within the normal range. The relationship between Thyopac ETR and the free Thyopac index is shown in figure 4. A significant correlation $\left(\gamma=+0.96, F_{0}>F^{1} 84(0.001)\right)$ was demonstrated between the two, although a regression equation was curvilinear rather than a straight line, as expressed by $y=71.67 x^{2}-88.40 x$ $+24 \cdot 18$.

\section{Discussion}

It is possible to calculate the free $T_{4}$ index from the $T_{4}$ value and $T_{3}$ resin uptake, because free $T_{4}$ is a function of $T_{4}$ and $T_{4}$-binding proteins in serum. The free $T_{4}$ indices of Clark et al (1965) and also of Goolden et al (1967) were based on the following equation: $K\left(\right.$ free $\left.T_{4}\right)=\left(\right.$ TBG-bound $\left.T_{4}\right) /($ free $T B G)$ $\tilde{E}\left(\right.$ total $\left.T_{4}\right) \times\left(T_{3}\right.$ resin uptake $)$. However, it is obvious that $T_{4}$ bound by $T B G$ is not linearly related to total $T_{4}$ in serum, because increasing amounts of $T_{4}$ are spilled over to $T_{4}$-binding prealbumin (TBPA) and to albumin (Ingbar and Freinkel, 1960). As a result, these free $T_{4}$ indices bore a curvilinear relationship to free $T_{4}$ values determined experimentally. In our previous paper (Hamada et al, 1970), a new free $\mathrm{T}_{4}$ index, PBI (or $\left.\mathrm{T}_{4}\right) \times$ Triosorb/(1-0.6 $\times$ Triosorb) was proposed, being derived from the following general equation for reversible binding equilibrium between $T_{4}$ and three $T_{4}$-binding proteins: free $T_{4}=\left(\right.$ total $\left.T_{4}\right) \div$ $\{$ KTBG (free TBG) + KTBPA(free TBPA) + KALB(free Albumin) \}. The new index was shown to bear a linear relationship to free $T_{4}$ values

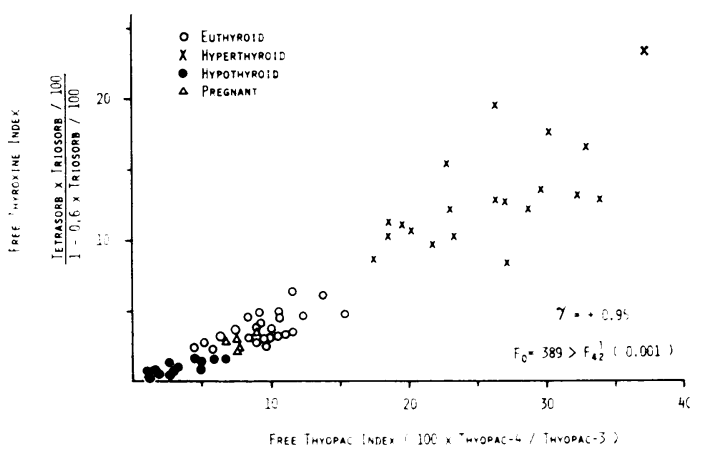

Fig 5 Relationship between free Thyopac index and our free $T_{4}$ index $\left(\frac{\text { Tetrasorb } \times \text { Triosorb } / 100}{1-0 \cdot 6 \times \text { Triosorb } / 100}\right)$ measured by equilibrium dialysis. It is shown in fig 5 that despite a significant correlation $(\gamma=$ +0.95 ), a curvilinear relationship exists between the free Thyopac index and free $T_{4}$, utilizing our free $\mathrm{T}_{4}$ index.

Two determinations of the $T_{4}$ level and $T_{3}$ resin uptake are necessary to calculate the free $\mathrm{T}_{4}$ indices. Recently, however, another indicator of free $T_{4}$ has been developed employing dual competitive binding analysis in which patient serum itself is added to one assay system together with extracted $\mathrm{T}_{4}$ (Mincey et al, 1971; Ashkar and Bezjian, 1972). Because changes in $\mathrm{T}_{4}$ level in pregnancy or TBG deficiency are accompanied by a parallel change in TBG, the abnormal resin uptake in such a case is normalized by enrichment of patient serum. The Thyopac ETR described here is based on the same principle, and has been demonstrated to be a useful indicator of free $\mathrm{T}_{4}$, the values irrespective of changes in TBG (figs 3 and 4).

It should be added that values obtained by this analysis are not in parallel with free $T_{4}$ levels in serum, because a certain amount of the TBG preparation is added for the assay. As shown in fig 4, Thyopac ETR values ranged only from 0.80 to 1.50 , representing a curvilinear relationship to the free Thyopac index. These characteristics were similar to those of Res-O-Mat ETR and normalized serum thyroxine (Mincey et al, 1971; Ashkar and Bezjian, 1972).

Using a single kit of Res-O-Mat ETR, Inada, Okabe, Kazama, Takayama, Haruna, and Takahashi (1973) determined both $\mathrm{T}_{4}$ and ETR values. After measurement of $T_{4}$, patient serum was added to the same vial to normalize the resin uptake. However, an irreversible phase in binding of thyroid hormone by resin (Goolden et al, 1965) might hinder the new equilibrium which is to be established between $T_{4}$ and added serum. In this respect the present method appears to be more appropriate because of reversible binding of $T_{4}$ with Sephadex.

The characteristic of dual competitive binding analysis necessarily leads to an unawareness of any abnormality in TBG content. This disadvantage can be corrected by a simultaneous determination of $T_{4}$, because a high or low $T_{4}$ value is to be observed, in pregnancy or TBG deficiency respectively, despite a normal value for ETR. Therefore, determination of both values appears more useful, although the Thyopac ETR alone can be measured by this procedure.

The authors wish to thank Miss Tadako Kosaka for her excellent technical assistance.

This work was supported in part by a Japan scientific research grant no. C-757094. 
References

Ashkar, F. S., and Bezjian, A. A. (1972). Use of normalized serum thyroxine $\left(T_{6} N\right)$ : a new approach to thyroid hormone measurement. J. Amer. med. Ass., 221, 1483-1485.

Clark, F., and Brown, H. J. (1970a). Evaluation of Thyopac-3 test in the in-vitro assessment of thyroid function. Brit. med. J., 1, 713-715.

Clark, F., and Brown, H.J.(1970b). Free thyroxine index. Brit.med.J., $2,543,672$.

Clark, F., and Horn, D. B. (1965). Assessment of thyroid function by the combined use of the serum protein-bound iodine and resin uptake of ${ }^{121}$ I-triiodothyronine. J. clin. Endocr., 25, 39-45.

Goolden, A. W. G., Gartside, J. M., and Osorio, C. (1965). An evaluation of the ${ }^{131}$ I-triiodothyronine resin sponge test. J. clin. Endocr., 25, 127-133.

Goolden, A. W. G., Gartside, J. M., and Sanderson, C. (1967). Thyroid status in pregnancy and in women taking oral contra- ceptives. Lancet, 1, 12-15.

Hamada, S., Nakagawa, T., Mori, T., and Torizuka, K. (1970). Reevaluation of thyroxine binding and free thyroxine in human serum by paper electrophoresis and equilibrium dialysis, and a new free thyroxine index. J. clin. Endocr., 31, 166-179.

Inada, M., Okabe, J., Kazama, Y., Takayama, H., Haruna, M., and Takahashi, H. (1973). Diagnosis of thyroid function by Res-O-Mat ETR test. II. Simultaneous determinations of the effective thyroxine ratio and thyroxine concentration by Res-O-Mat ETR test. Jap. J. nucl. Med., 10, 37-43.

Ingbar, S. H., and Freinkel, N. (1960). Regulation of the peripheral metabolism of the thyroid hormones. Recent Progr. Hormone Res., 16, 353-403.

Mincey, E. K., Thorson, S. C., Brown, J. L., Morrison, R. T., and McIntosh, H. W. (1971). A new parameter of thyroid functionThe Effective Thyroxine Ratio. J. nucl. Med., 13, 165-168.

Robbins, J., and Rall, J. E. (1960). Proteins associated with the thyroid hormones. Physiol. Rev., 40, 415-489. 